Check for updates

Cite this: RSC Adv., 2018, 8, 41308

Received 17th October 2018

Accepted 23rd November 2018

DOI: $10.1039 / \mathrm{c} 8 \mathrm{ra} 08587 \mathrm{k}$

rsc.li/rsc-advances

\section{Study of hydrogen explosion control measures by using L-phenylalanine for aluminum wet dust removal systems}

\author{
Xin Zheng, ${ }^{a}$ Kaili Xu, ${ }^{* a}$ Yantong Wang, ${ }^{\text {bc }}$ Ruiqing Shen ${ }^{\mathrm{b}}$ and Qingsheng Wang (D) *bd
}

Wet dust removal systems are an effective design for preventing aluminum dust explosion in the process of metal polishing. However, wet dust removal systems pose hydrogen fire and explosion risks because aluminum dust can react with water to produce hydrogen gas. According to previous studies, Lphenylalanine can be used to solve the corrosion problem of metal slabs. In this work, a hydrogen inhibition method was proposed to inhibit hydrogen production in wet dust removal systems by using L-phenylalanine. The hydrogen evolution curves of aluminum particles reacting with different concentrations of L-phenylalanine solutions obtained via hydrogen inhibition experiments revealed that when the concentration of L-phenylalanine solutions reached $20 \mathrm{~g} \mathrm{~L}^{-1}$, essentially no hydrogen gas was produced. Scanning electron microscopy (SEM) and energy dispersive spectroscopy (EDS) were used to characterize the aluminum particles before and after the reaction. This work shows that L-phenylalanine is a good inhibitor. The adsorption of L-phenylalanine on the aluminum particle surface obeys the Langmuir adsorption isotherm. Additionally, Fourier transform infrared (FTIR) analysis was conducted to explain the physicochemical mechanism of the L-phenylalanine inhibition of hydrogen production. L-Phenylalanine is an environmentally friendly inhibitor and hence can be used in wet dust removal systems for the treatment of aluminum dust, which can reduce the hydrogen fire and explosion risk.

\section{Introduction}

Aluminum alloys have the following advantages: low specific gravity, high strength, and good physical and chemical properties. Because of these beneficial properties, aluminum and aluminum alloys have replaced traditional iron-based materials in some fields in recent years and they are among the most widely used nonferrous metal structural materials in industrial applications. Specifically, they have been widely used in the aviation, aerospace, automobile, mechanical manufacturing, shipbuilding and chemical industries. ${ }^{1}$ Before being used in any industrial application, raw metal needs to be polished first to meet the corresponding industrial requirement. During the polishing process, a large amount of metal dust is produced. Aluminum dust is a type of combustible dust. ${ }^{2}$ When the concentration of aluminum dust dispersed in the air reaches

${ }^{a}$ College of Resources and Civil Engineering, Northeastern University, Shenyang, Liaoning, China

${ }^{b}$ Department of Fire Protection \& Safety, Oklahoma State University, Stillwater, OK, USA

'Sinochem Energy Saving and Environmental Protection Holding (Beijing) Co., Ltd, Beijing, China

${ }^{d}$ Mary Kay O'Connor Process Safety Center, Artie McFerrin Department of Chemical Engineering, Texas A\&M University, College Station, TX, USA. E-mail: qwang@ tamu.edu a certain explosion limit, serious dust explosion accidents may occur. Eckhoff noted that accidental dust explosions remain a persistent hazard in processing industries. ${ }^{3}$ In addition, Taveau J. et al. reviewed seven particular accidents that occurred at aluminum finishing facilities. ${ }^{4}$ Dust explosion accidents have occurred in China in recent years due to the grinding and polishing of aluminum, and these accidents resulted in considerable casualties and property losses. On the morning of August $2^{\text {nd }}, 2014$, a catastrophic aluminum-alloy dust explosion accident occurred in a polishing workshop owned by Kunshan Zhongrong Metal Products Co., Ltd. Seventy-five people lost their lives almost immediately, and another 185 were injured. ${ }^{5}$ The application of a wet dust removal system can effectively mitigate the occurrence of aluminum dust explosions. However, aluminum dust can react with water to produce hydrogen. ${ }^{6}$ In 2001, due to the reaction of aluminum magnesium alloy dust with water, in which hydrogen was produced, a dust removal system exploded in a polishing workshop of a mobile phone company in Japan, resulting in 10 people being injured. In 2011, a hydrogen explosion occurred in an aluminum-magnesiumalloy shell processing workshop in China due to the use of water spray to reduce dust, in which 21 people were injured. ${ }^{7}$ According to NFPA 484-2015, explosion-proof, anti-static and venting explosion measures should be adopted in wet dust removal systems. Moreover, all the electrical components of 
these devices should be explosion-proof. By taking these safety measures, the probability of hydrogen explosion accidents can be reduced; however, these safety measures cannot inherently prevent the hydrogen explosion problem, and the cost of installing these devices is very high. If the reaction itself between aluminum dust and water in a wet dust removal system can be controlled, the risk of hydrogen explosion can be eliminated significantly.

Previous studies have focused on promoting the reaction between aluminum particles and water. ${ }^{8-13}$ Few researchers have attempted to inhibit the hydrogen-producing reaction between aluminum and water. Wang $\mathrm{Y}$. proposed the use of $\mathrm{K}_{2} \mathrm{Cr}_{2} \mathrm{O}_{7}, \mathrm{Na}_{2} \mathrm{Cr}_{2} \mathrm{O}_{7} \cdot 2 \mathrm{H}_{2} \mathrm{O}, \quad \mathrm{Cr}\left(\mathrm{NO}_{3}\right)_{3} \cdot 9 \mathrm{H}_{2} \mathrm{O}$, and $\mathrm{CrK}\left(\mathrm{SO}_{4}\right)_{2^{-}}$ $\cdot 12 \mathrm{H}_{2} \mathrm{O}$, and $\mathrm{Xu} \mathrm{K}$. proposed the use of $\mathrm{CeCl}_{3}$ to inhibit the reactions between aluminum and water in wet dust removal systems. ${ }^{14-17}$ These inhibitors can effectively constrain the reaction between aluminum dust and water and intrinsically prevent the hydrogen explosions in wet dust removal systems. However, chromate is toxic, and the long-term exposure to chromate can cause cancer. ${ }^{18}$ Moreover, $\mathrm{CeCl}_{3}$ emits poisonous gas at high temperatures. If a fire and an explosion occur, secondary disasters will also occur due to toxic gases produced. Therefore, a safe and non-toxic inhibitor must be identified. The reactions between aluminum and water are essentially aluminum corrosion reactions. ${ }^{19}$ Zheng X. used electrochemical methods to evaluate the corrosion inhibition performance and inhibition mechanism of L-phenylalanine for Q235 steel in $0.5 \mathrm{~mol} \mathrm{~L}^{-1} \mathrm{H}_{2} \mathrm{SO}_{4}$ solutions. ${ }^{20} \mathrm{~L}$-Phenylalanine is an important food additive, and one of the essential amino acids of the human body. Starting from this point, L-phenylalanine is employed as a potential inhibitor to mitigate the reaction between aluminum and water, which is experimentally investigated in this study.

The objectives of this study are as follows: ${ }^{1} \mathrm{~L}$-phenylalanine solutions are used to control reactions between water and aluminum powder at different concentrations using an aluminum and water reaction tester. The inhibitory effect and the most suitable inhibitory concentration of L-phenylalanine are obtained; ${ }^{2}$ scanning electron microscopy (SEM), energy dispersive X-ray spectroscopy (EDS) and a chemical kinetic model are used to prove the existence of an inhibition film on the aluminum particle surface; ${ }^{3}$ the Fourier transform infrared (FTIR) and adsorption isotherms are used to analyse the reaction mechanism and determine how the reaction between aluminum and water can be inhibited. The proposed method offers new insights into the hydrogen explosion prevention capability of wet dust removal systems.

\section{Experiments}

\subsection{Hydrogen inhibition experiment}

The experiments were conducted using the aluminum and water reaction tester shown in Fig. 1.

According to the work by Wang Y. et al. ${ }^{14-17}$ the initial temperature and pressure for each experiment were set to $50{ }^{\circ} \mathrm{C}$ and $100 \mathrm{kPa}$, respectively. In addition, the reaction between aluminum particles and water can produce only hydrogen; thus, the change in the mole of the generated hydrogen can be characterized by the change of the pressure within the reactor. Hydrogen evolution $\alpha$ is used to represent the hydrogen production of different reactions:

$$
\alpha=\frac{\left(P-P_{\text {initial }}\right)\left(V-V_{\text {solution }}\right)}{n_{0} R T}
$$

$\alpha$-hydrogen evolution, $P$-gas pressure in the reactor, $\mathrm{kPa}, P_{\text {initial }}{ }^{-}$ initial pressure value in the reactor, $\mathrm{kPa}, V$-reactor volume, $\mathrm{L}$,

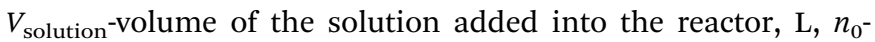
mole of aluminum powder added into the reactor, mol, $R$-ideal gas constant, $8.314 \mathrm{~J}\left(\mathrm{~mol}^{-1} \mathrm{~K}^{-1}\right), T$-gas temperature, $\mathrm{K}$.

An aluminum powder production company in Shanghai, China, was selected as the field research site, and a wet dust removal system was used to collect aluminum dust released into the air. To better understand the detailed characteristics of the aluminum dust sample, a laser diffraction analyser (Microtrac
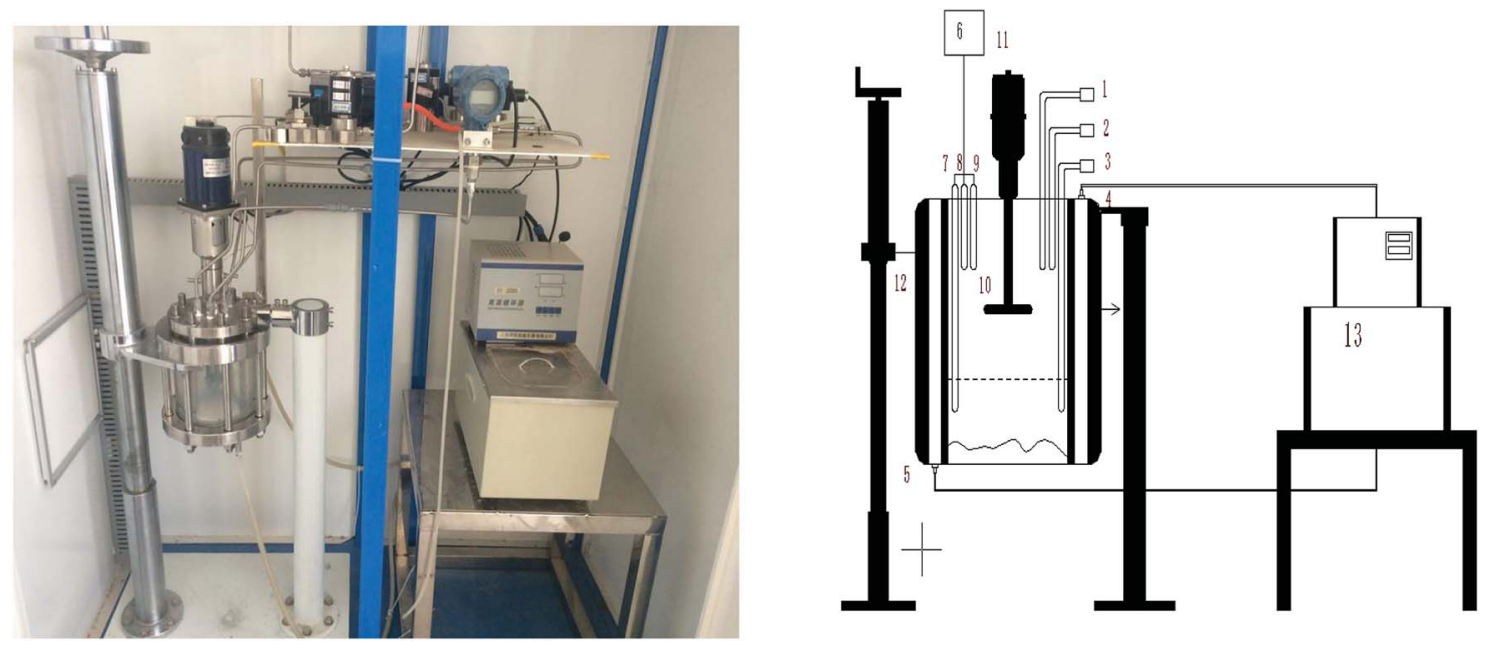

Fig. 1 Physical and schematic diagram of the experimental setup ((1) positive pressure pump, (2) vacuum pump, (3) flowmeter, (4) circulating water outlet hole, (5) circulating water inlet hole, (6) PC, (7) temperature sensor, (8) pressure sensor, (9) exhaust solenoid valve, (10) aluminum tray, (11) motor, (12) double-layer quartz glass reactor, (13) high-temperature water circulator). 


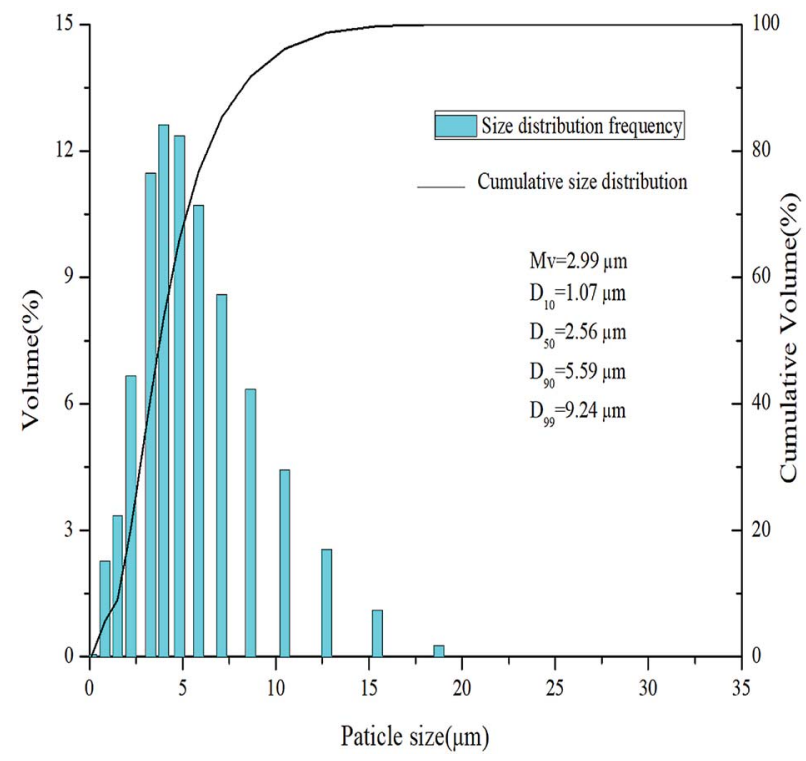

Fig. 2 Particle size distribution.

s3500) was used to obtain the aluminum dust size distribution. The results are shown in Fig. 2. Most of the particles have a size of approximately $2 \mu \mathrm{m}$. Fig. 3 shows a SEM image of the aluminum dust. The surface of the aluminum dust is smooth and compact. L-Phenylalanine (analytical reagent grade, Sinopharm Chemical Reagent Co., Ltd., Shanghai, China) and deionized water were applied to prepare a certain concentration of the solution.

Before the start of the experiments, $\mathrm{H}_{2}$ was injected into the reactor at $500 \mathrm{kPa}$ to perform an air tightness test, with the pressure sensor recording the pressure value during the air tightness test. The temperature was maintained at $50{ }^{\circ} \mathrm{C}$, and the test was conducted for $24 \mathrm{~h}$. After $24 \mathrm{~h}$, the pressure inside the reactor remained at $500 \mathrm{kPa}$. In each experiment, $200 \mathrm{~mL}$ of solution was added to the reactor. The change in the molar quantity of the generated hydrogen can be characterized by the change of the pressure in the reactor.

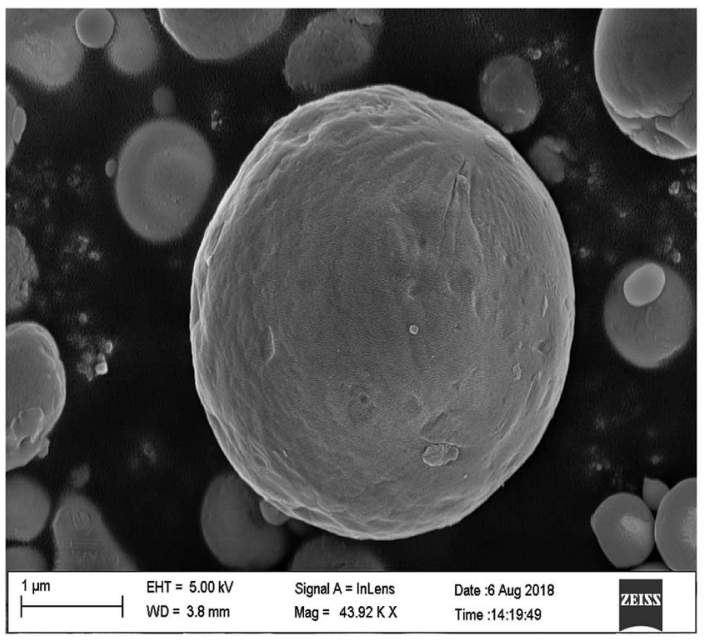

Fig. 3 A SEM image of the aluminum particle.

\subsection{Characterizations}

The appearances of the original aluminum particle surface and the aluminum particle surface after reacting with different solutions were characterized using a SEM (ULTRA PLIS, Zeiss Microscope Company, Germany). EDS was used to conduct a comparative analysis of the atomic percentages of oxygen and aluminum in the surface films on the aluminum particles after reacting with $2.50 \mathrm{~g} \mathrm{~L}^{-1}, 8.25 \mathrm{~g} \mathrm{~L}^{-1}$ and $24.80 \mathrm{~g} \mathrm{~L}^{-1}$ L-phenylalanine solutions. To identify the main functional groups of the inhibitor, aluminum dust reacted with $24.80 \mathrm{~g} \mathrm{~L}^{-1}$ L-phenylalanine solution was tested by FTIR (Nicolet Nexus 470, $5145 \mathrm{~nm}$, $200 \mathrm{mw}, 450-4000 \mathrm{~cm}^{-1}$ ).

\section{Results and discussion}

\subsection{Results of inhibition experiments}

Fig. 4 shows the hydrogen evolution curves of the reaction between aluminum dust and the s-phenylalanine solution of different concentrations. The reactions lasted for approximately $9 \mathrm{~h}$. As the concentration of L-phenylalanine solution increased, the hydrogen evolution $\alpha$ gradually decreased. When the concentration of the $\mathrm{L}^{-}$ phenylalanine solution was greater than or equal to $20 \mathrm{~g} \mathrm{~L}^{-1}$, the hydrogen evolution $\alpha$ approached 0 , indicating that hydrogen production was almost completely inhibited.

\subsection{SEM-EDS}

The SEM results for three samples (after aluminum particles reacted with $2.50 \mathrm{~g} \mathrm{~L}^{-1}, 8.25 \mathrm{~g} \mathrm{~L}^{-1}$ and $24.80 \mathrm{~g} \mathrm{~L}^{-1} \mathrm{~L}$-phenylalanine solutions) are shown in Fig. 5-7. As shown in Fig. 5(a), when the aluminum particles reacted with the $2.50 \mathrm{~g} \mathrm{~L}^{-1} \mathrm{~L}^{-}$ phenylalanine solution, under the action of t-phenylalanine, the aluminum particles were clustered together. At this time, no L-phenylalanine protective film existed on the aluminum particle surface. According to the work by Wang Y. et al. ${ }^{14-16}$ and $\mathrm{Xu} \mathrm{K}$. et al., ${ }^{17}$ after all the $\mathrm{Al}_{2} \mathrm{O}_{3}$ available on the surface has reacted with water and formed $\mathrm{Al}(\mathrm{OH})_{3}$, the aluminum core can react with $\mathrm{Al}(\mathrm{OH})_{3}$ and generate hydrogen. Fig. 8 shows that around the aluminum core, many ellipsoidal hydrogen bubbles are uniformly arranged. With the accumulation of hydrogen, the $\mathrm{Al}(\mathrm{OH})_{3}$ film experiences increased tension. When the tension is larger than the critical tension of the $\mathrm{Al}(\mathrm{OH})_{3}$, the film will rupture, with the hydrogen being released. In Fig. 5(b), the morphology of the surface for the agglomeration is enlarged (the original picture is shown in Fig. 5(a)) and it also shows the morphology of the rupture of the $\mathrm{Al}(\mathrm{OH})_{3}$ film. Fig. 6 is the SEM image of aluminum particles after reacting with the $8.25 \mathrm{~g} \mathrm{~L}^{-1} \mathrm{~L}^{-}$ phenylalanine solution. Clearly, a protective film was formed on the surface of the aluminum particles, but it was not a compact protective film yet. Fig. 7 is the SEM image of aluminum particles after reacting with the $24.80 \mathrm{~g} \mathrm{~L}^{-1}$ L-phenylalanine solution. Clearly, the aluminum particle surface was very smooth and compact. The hydrogen evolution curve shows that the reaction between aluminum particles and water was completely inhibited.

Fig. 9 presents EDS element analysis images of aluminum particles after reacting with $2.50 \mathrm{~g} \mathrm{~L}^{-1}, 8.25 \mathrm{~g} \mathrm{~L}^{-1}$ and $24.80 \mathrm{~g}$ 


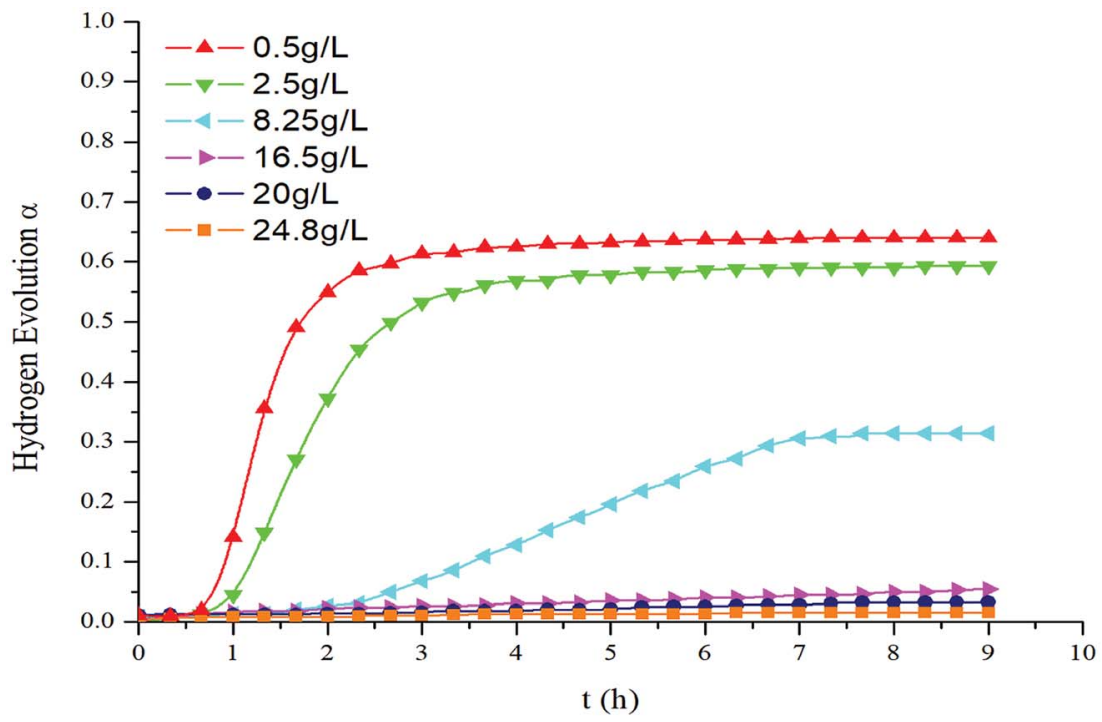

Fig. 4 Hydrogen evolution curves of aluminum particles when reacting with L-phenylalanine solution of different concentrations.

$\mathrm{L}^{-1}$ L-phenylalanine solutions, respectively. For these three cases, the atomic percentages of aluminum and oxygen elements were shown in Table 1. From Table 1, as the concentration of the L-phenylalanine increases in the solution, the atomic percentage of aluminum element in the reaction products of the aluminum particles and L-phenylalanine solution increases, and the atomic percentage of the oxygen element decreases. In particular, in the reaction products of aluminum particles and the $24.80 \mathrm{~g} \mathrm{~L}^{-1}$ L-phenylalanine solution, the atomic percentage of aluminum was as high as $96.52 \%$, indicating that the inhibitor effectively prevents the reaction between aluminum and water.

According to previous studies, the hydrogen evolution $\alpha$ and reaction rate should fit eqn (2) during the reaction. ${ }^{21}$ The corresponding rate constant was calculated, as shown in Table 2 .
As the L-phenylalanine concentration in solution increased, the rate constant decreased. Table 2 shows that when the $\mathrm{L}^{-}$ phenylalanine concentration in solution was greater than or equal to $20 \mathrm{~g} \mathrm{~L}^{-1}$, the reaction rate constant was 0 , indicating that the reaction between aluminum and water was completely suppressed.

$$
1-(1-\alpha)^{1 / 3}=k t
$$

$\alpha$-hydrogen evolution, $k$-rate constant, $\mathrm{h}^{-1}, t$-reaction time, $\mathrm{h}$.

\section{$3.3 \quad$ FTIR}

A FTIR analysis of the L-phenylalanine sample is shown in Fig. 10. Additionally, a FTIR analysis of the product obtained
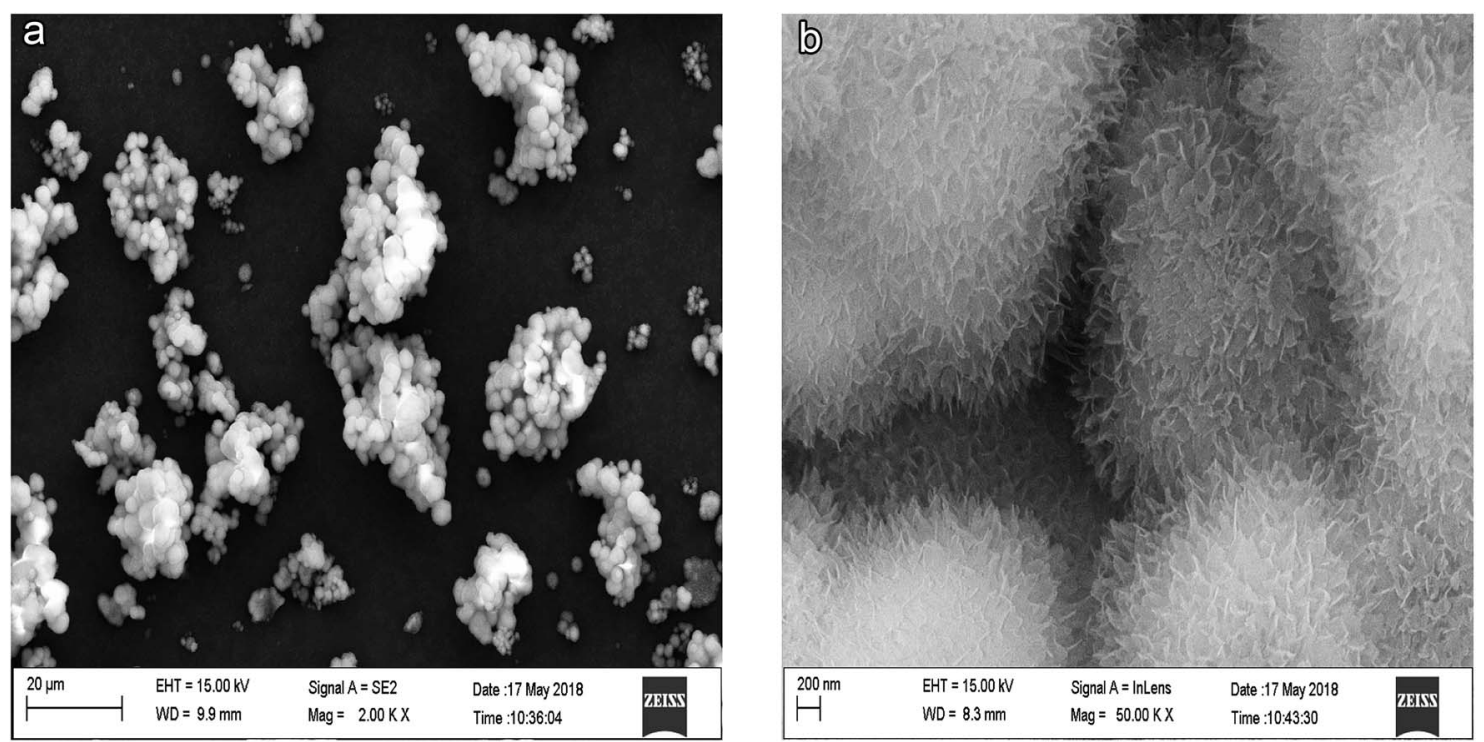

Fig. 5 (a) SEM image of the aluminum particles after reacting with the $2.50 \mathrm{~g} \mathrm{~L}^{-1} \mathrm{~L}$-phenylalanine solution. (b) Morphology of the rupture of the $\mathrm{Al}(\mathrm{OH})_{3}$ film. 


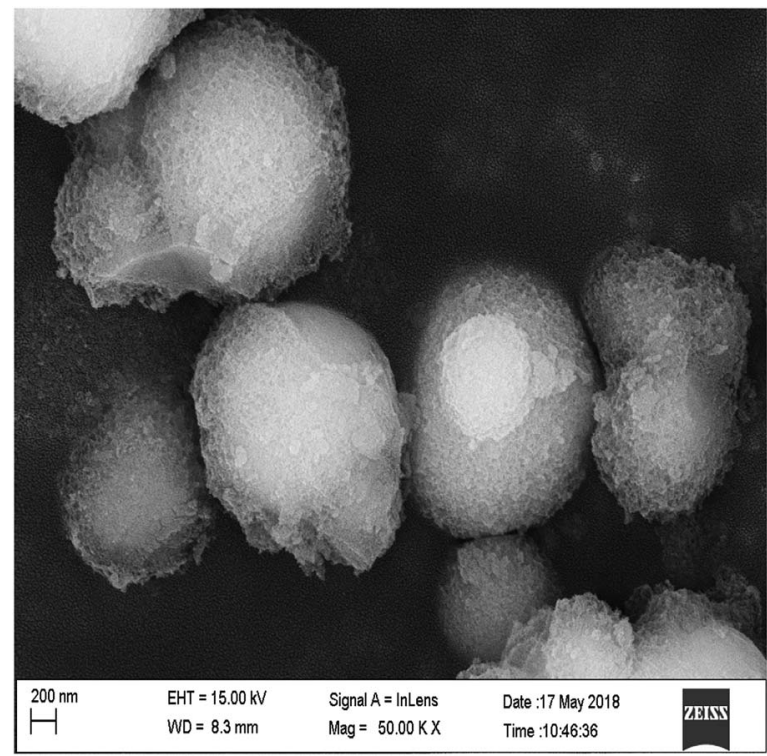

Fig. 6 SEM image of the aluminum particles after reacting with the $8.25 \mathrm{~g} \mathrm{~L}^{-1} \mathrm{~L}$-phenylalanine solution.

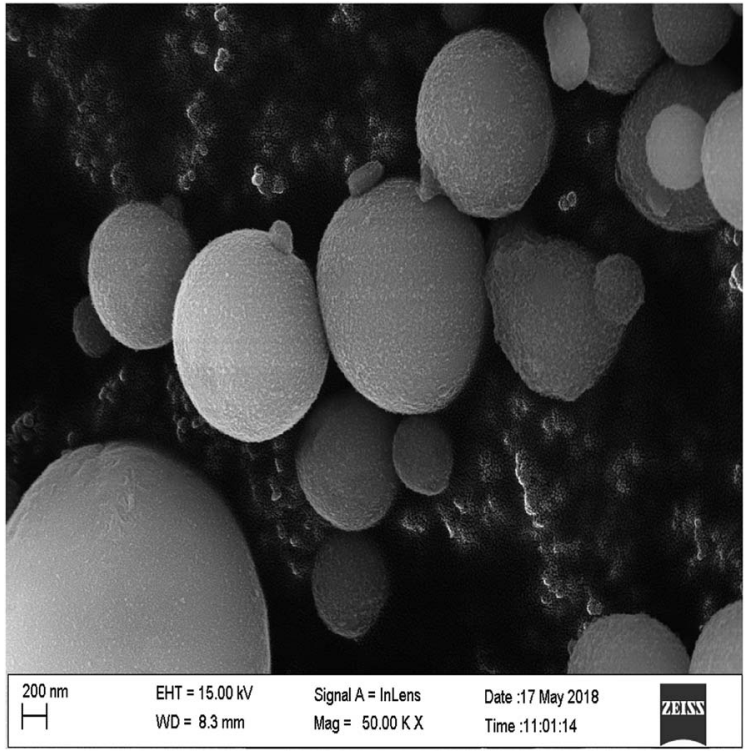

Fig. 7 SEM image of the aluminum particles after reacting with the $24.89 \mathrm{~g} \mathrm{~L}^{-1} \mathrm{~L}$-phenylalanine solution.

from the reaction between aluminum particle and $24.80 \mathrm{~g} \mathrm{~L}^{-1} \mathrm{~L}^{-}$ phenylalanine solution is shown in Fig. 11.

According to the study by Zhang W., ${ }^{22}$ a strong absorption peak at $3414 \mathrm{~cm}^{-1}$ indicates that $-\mathrm{OH}$ exists. The absorption peak at $3000 \mathrm{~cm}^{-1}$ is generated by $\mathrm{N}-\mathrm{H}$ stretching vibration, indicating that $-\mathrm{NH}_{2}$ exists. At $2830-2930 \mathrm{~cm}^{-1}$, a relatively weak $\mathrm{C}-\mathrm{H}$ absorption peak exists for the alkane structure, and near $1600 \mathrm{~cm}^{-1}$, an absorption peak due to the vibration of the aromatic ring $(\mathrm{C}=\mathrm{C})$ exists. According to the work by Geng J. ${ }^{23}$ the absorption peak at approximately $2100 \mathrm{~cm}^{-1}$ is the characteristic absorption peak of $\mathrm{L}$-amino acids, the absorption peak at approximately $1563 \mathrm{~cm}^{-1}$ is the carboxyl group absorption peak, and the absorption peak at approximately $1160 \mathrm{~cm}^{-1}$ is

$$
2 \mathrm{Al}(\mathrm{OH})_{3}+2 \mathrm{Al} \longrightarrow 2 \mathrm{Al}_{2} \mathrm{O}_{3}+3 \mathrm{H}_{2} \uparrow
$$

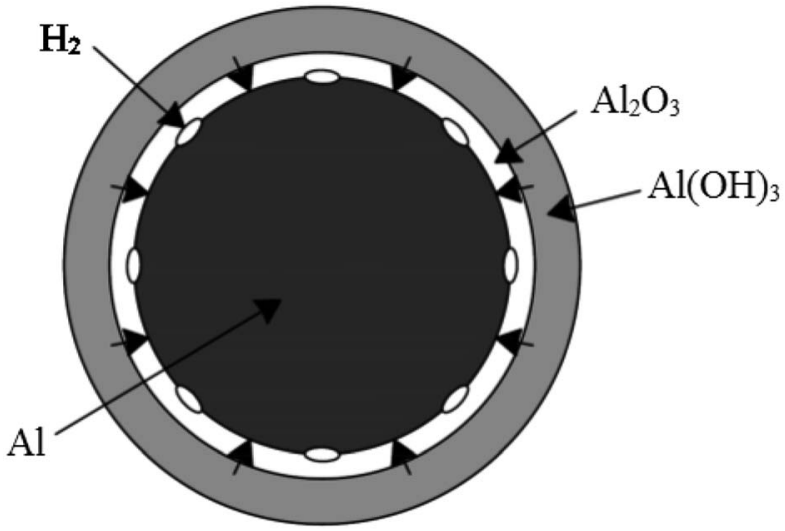

Fig. 8 The hydrogen production reaction.

the swing absorption peak of $-\mathrm{NH}_{2}$. The important IR absorption bands of L-phenylalanine are shown in Table 3, and the IR absorption bands of the product obtained from the reaction of aluminum particle and $24.80 \mathrm{~g} \mathrm{~L}^{-1} \mathrm{~L}$-phenylalanine are shown in Table 4. Table 3 indicates that the absorption peak of the carbonyl stretching vibration at $1563.34 \mathrm{~cm}^{-1}$ coincides with the strong absorption peak at $3440.94 \mathrm{~cm}^{-1}$, suggesting the existence of a $-\mathrm{COOH}$ structure. Additionally, the absorption peak of $\mathrm{C}-\mathrm{H}$ at $2963.34 \mathrm{~cm}^{-1}$ coincides with the absorption peak of $\mathrm{C}=\mathrm{C}$ at $1625.33 \mathrm{~cm}^{-1}$, indicating the existence of a benzene ring. The molecular structure of $\mathrm{L}$-phenylalanine is shown in Fig. 12.

\section{Physicochemical mechanisms}

As a mechanism that prevents aluminum from reacting with water to produce hydrogen, the protective film that forms on the surface of aluminum particles can be divided into a precipitation type and an adsorption type. The inhibitors proposed by Wang $\mathrm{Y}^{14-16}$ and $\mathrm{Xu} \mathrm{K.}{ }^{17}$ to inhibit the reaction between aluminum particles and water are precipitating inhibitors. Most of the adsorbent inhibitors are organic materials, which have polar genes and can be adsorbed by metal surface charges.

The Langmuir adsorption isotherm is shown in eqn (3), the detailed derivation of the eqn (3) can be found in the work by Helal. ${ }^{24} \mathrm{~A}$ linear relationship can be obtained on plotting $C / \theta$ as a function of $C$, with a slope close to 1 , and the value of the intercept is the reciprocal of $K$.

The results of which are shown in Table 5. In addition, the linear correlation of $C / \theta-C$ for the s-phenylalanine inhibitor is shown in Fig. 13. According to the study by Li W. H. ${ }^{25}$ the correlation coefficient and slope are both close to 1 , which indicates the adsorption model of L-phenylalanine on the surface of aluminum particles agrees with the Langmuir adsorption isotherm.

$$
\frac{C}{\theta}=\frac{1}{K}+C
$$



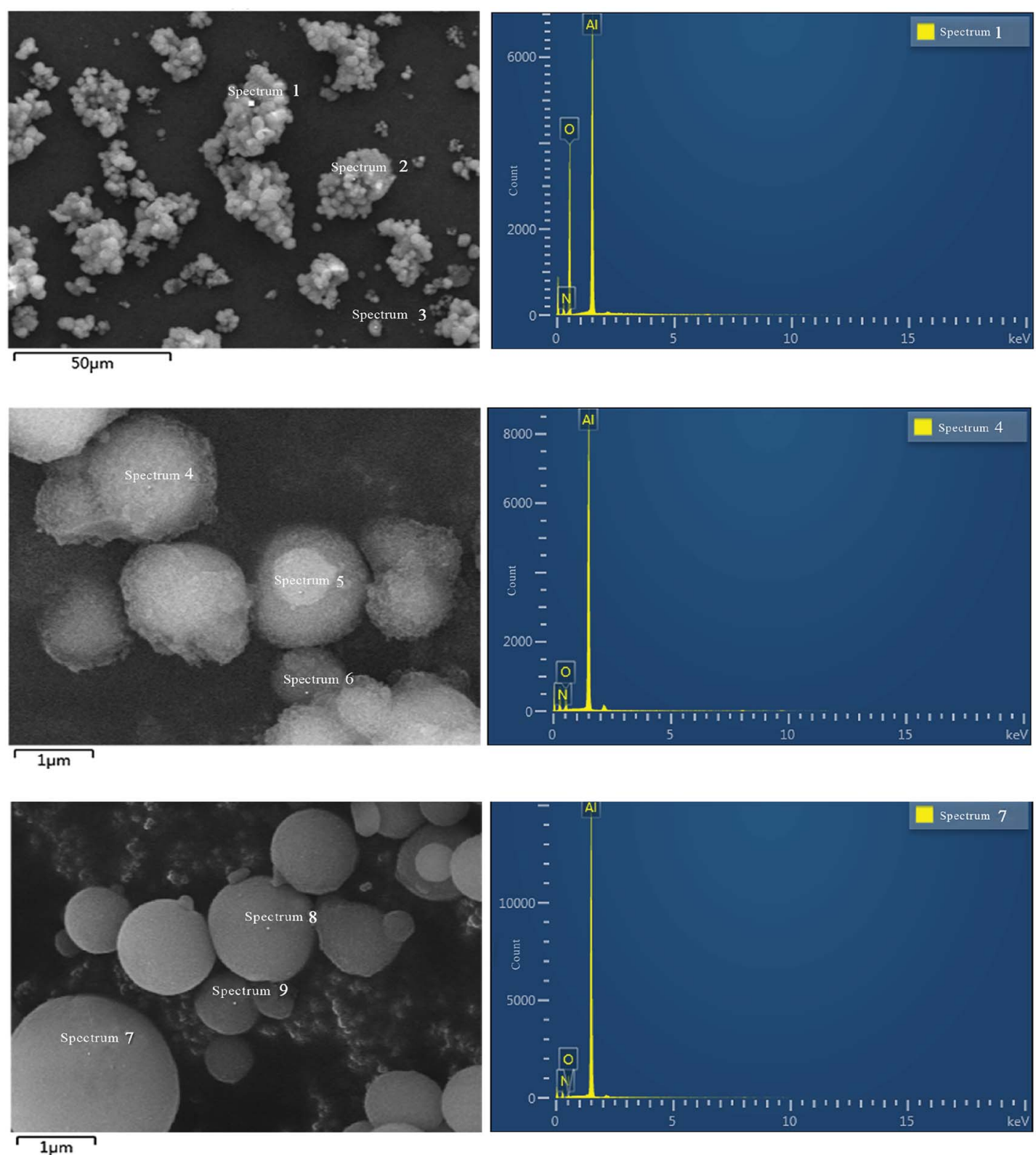

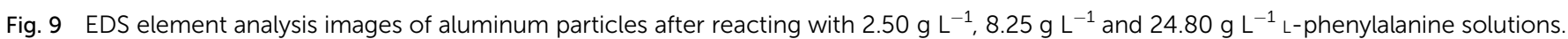

$C$-mass concentration of inhibitors, g $\mathrm{L}^{-1}, K$-adsorption equilibrium constant, $\mathrm{L} \mathrm{g}^{-1}, \theta$-surface coverage.

L-Phenylalanine is an adsorption inhibitor. The data in Table

4 suggest that the characteristic absorption peaks of $\mathrm{L}^{-}$

Table 1 Atomic percentage of aluminum and oxygen elements in the reaction products

\begin{tabular}{lll}
\hline EDS elemental analysis & Element & Percentage \\
\hline \multirow{2}{*}{$2.50 \mathrm{~g} \mathrm{~L}^{-1}$ L-phenylalanine solution } & $\mathrm{O}$ & 62.73 \\
$8.25 \mathrm{~g} \mathrm{~L}^{-1}$ L-phenylalanine solution & $\mathrm{Al}$ & 37.27 \\
$24.80 \mathrm{~g} \mathrm{~L}^{-1}$ L-phenylalanine solution & $\mathrm{O}$ & 26.30 \\
& $\mathrm{O}$ & 73.70 \\
& $\mathrm{Al}$ & 3.48 \\
\end{tabular}

phenylalanine disappear after the reaction involving aluminum particles and L-phenylalanine. This result proves that a complexation reaction between aluminum ions and phenylalanine has occurred. Additionally, the stretching vibration absorption peak of $-\mathrm{NH}_{2}$ at $3065.88 \mathrm{~cm}^{-1}$ is displaced, and the

\section{Table 2 The reaction rate constant}

\begin{tabular}{ll}
\hline L-Phenylalanine $\left(\mathrm{g} \mathrm{L}^{-1}\right)$ & $k\left(\mathrm{~h}^{-1}\right)$ \\
\hline 0.5 & 0.17732 \\
2.5 & 0.08814 \\
8.25 & 0.05488 \\
16.5 & 0.00157 \\
20 & 0 \\
24.8 & 0
\end{tabular}




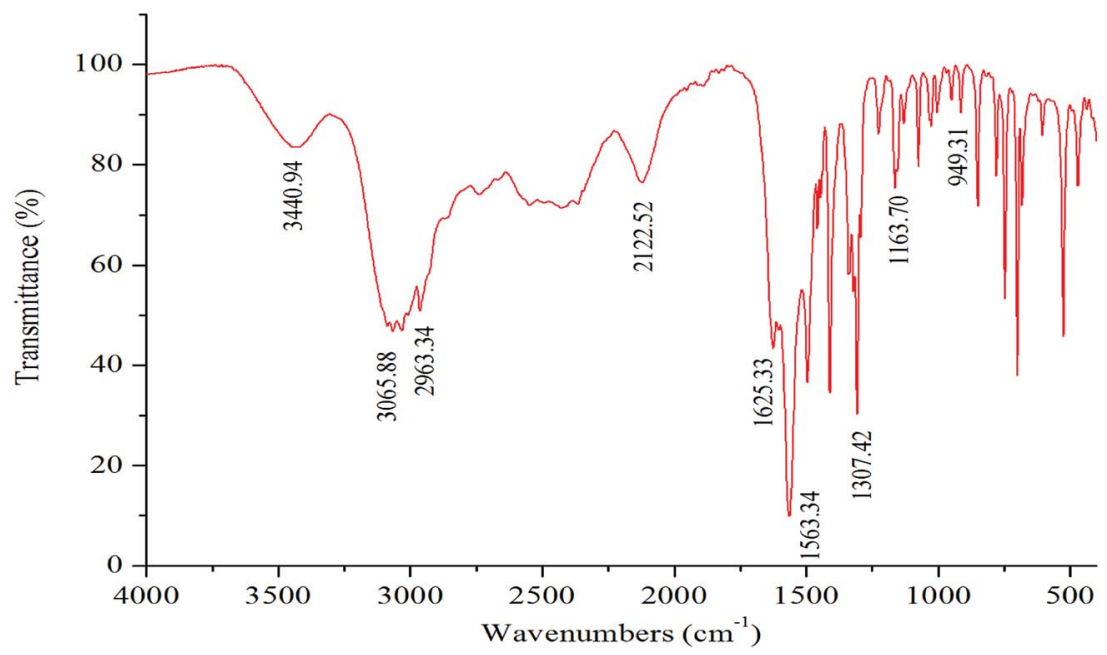

Fig. 10 FTIR analysis of L-phenylalanine.

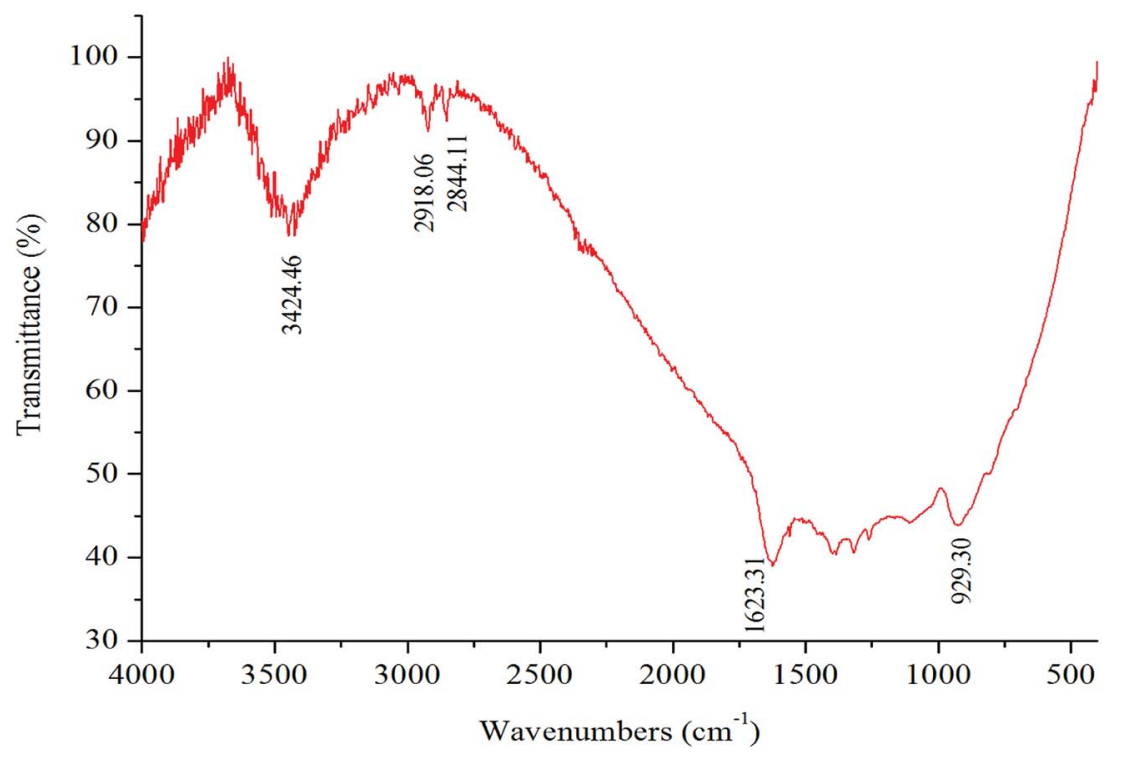

Fig. 11 FTIR analysis of L-phenylalanine after reaction.

absorption peak at $1163.70 \mathrm{~cm}^{-1}$ disappears, indicating that the amino group is involved in the complexation reaction. Moreover, the absorption peak of $-\mathrm{COO}^{-}$at $1563.34 \mathrm{~cm}^{-1}$ disappears, and a $-\mathrm{COH}$ absorption peak is observed at $929.30 \mathrm{~cm}^{-1}$,

Table 3 The important IR absorption bands of L-phenylalanine

\begin{tabular}{ll}
\hline Absorption peak $\left(\mathrm{cm}^{-1}\right)$ & Absorption peak attribution \\
\hline 3440.94 & $-\mathrm{OH}$ \\
3065.88 & $-\mathrm{NH}_{2}$ \\
2963.34 & $\mathrm{C}-\mathrm{H}$ \\
2122.52 & Characteristic absorption \\
& peak of L-amino acid \\
1625.33 & $\mathrm{C}=\mathrm{C}$ \\
1563.34 & $-\mathrm{COO}^{-}$ \\
1163.70 & $-\mathrm{NH}_{2}$ \\
949.31 & $-\mathrm{COH}$
\end{tabular}

indicating that the carboxyl group is involved in the complexation reaction. The structure of the reaction products of $\mathrm{L}^{-}$ phenylalanine and aluminum was deduced based on the characteristics of the IR spectra and elemental analysis. The possible structure of the reaction product is shown in Fig. 14. L-Phenylalanine contains a non-polar benzene ring, polar group $\left(-\mathrm{NH}_{2}\right)$

Table 4 The important IR absorption bands of the product obtained from the reaction of aluminum particle and $24.80 \mathrm{~g} \mathrm{~L}^{-1} \mathrm{~L}-$ phenylalanine

\begin{tabular}{ll}
\hline Absorption peak $\left(\mathrm{cm}^{-1}\right)$ & Absorption peak attribution \\
\hline 3424.46 & $-\mathrm{OH}$ \\
2918.05 & $-\mathrm{NH}_{2}$ \\
2844.11 & $\mathrm{C}-\mathrm{H}$ \\
1623.31 & $\mathrm{C}=\mathrm{C}$ \\
929.30 & $-\mathrm{COH}$
\end{tabular}



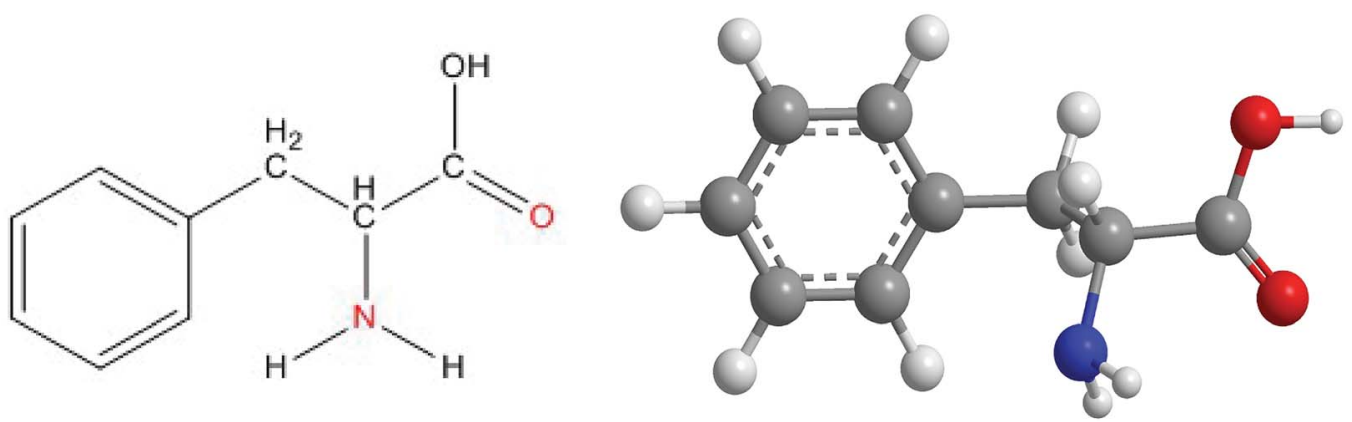

Fig. 12 The molecular structure of L-phenylalanine (grey- $\mathrm{C}$, white- $\mathrm{H}$, red-O and blue- N).

Table 5 Linear regression parameters of $C / \theta-C$

\begin{tabular}{llll}
\hline Inhibitor & $\begin{array}{l}\text { Correlation } \\
\text { coefficient }(r)\end{array}$ & Slope & $\begin{array}{l}\text { Absorption equilibrium } \\
\text { constant }(K) /\left(\mathrm{L} \mathrm{g}^{-1}\right)\end{array}$ \\
\hline L-Phenylalanine & 0.9763 & 0.9091 & 0.3565
\end{tabular}

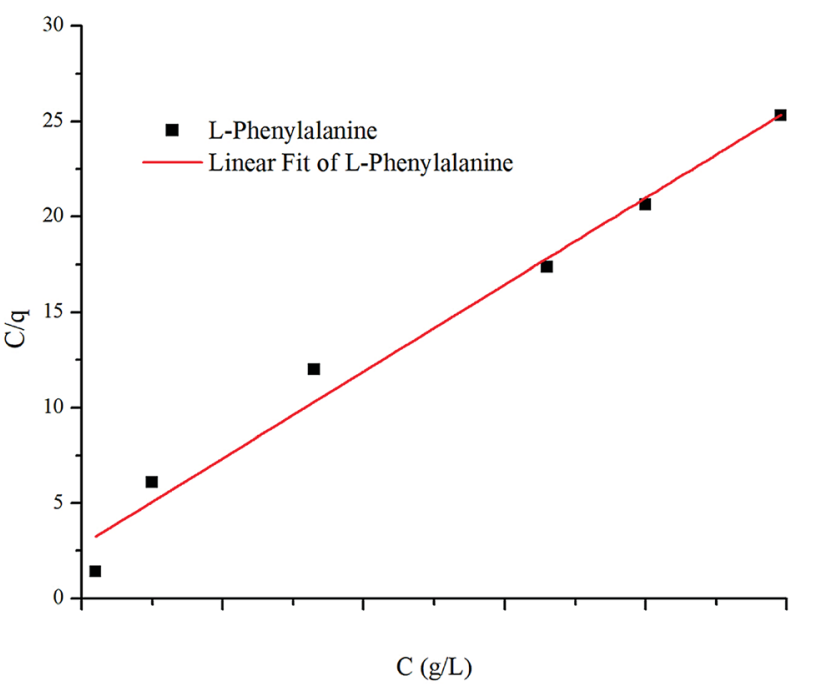

Fig. 13 Langmuir fitting curve of L-phenylalanine.

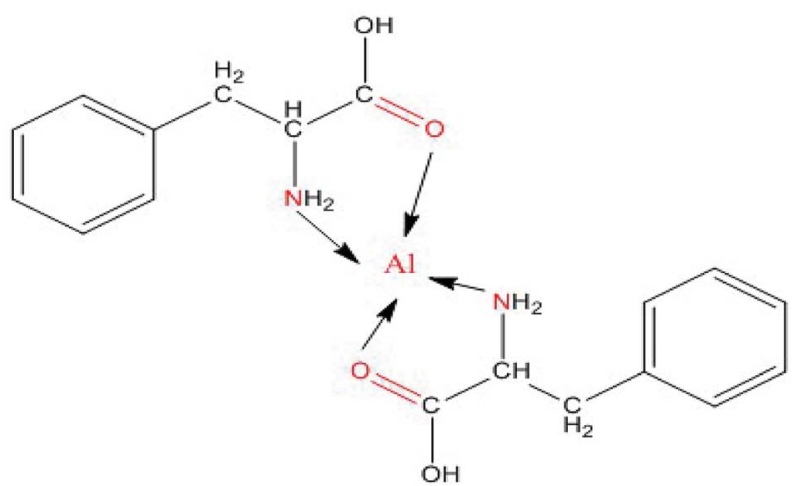

Fig. 14 The possible structure of the reaction products of L-phenylalanine and aluminum particle. and carboxyl group $(-\mathrm{COOH})$. The $\mathrm{N}$ atom contains the lone electrons pairs, which can bind with $\mathrm{Al}^{3+}$ and adsorb onto the surface of the aluminum particle. The hydrophilic carboxyl group $(-\mathrm{COOH})$ has a negative charge and is able to provide electrons for the blank orbit of aluminum. Therefore, a stable and compact chemical adsorption protective film can be formed on the aluminum surface. The hydrophobic benzene ring is arranged upwards to separate the metal surface from water and inhibit the reaction of aluminum particle and water.

\section{Conclusions}

At an industrial site, particularly one with a wet dust removal system used for the treatment of aluminum dust, the existence of hydrogen can greatly increase the risk of fire and explosion. Based on the theory of inherent safety, L-phenylalanine solution was proposed to inhibit hydrogen production. When the concentration of $\mathrm{L}$-phenylalanine in the solution reaches $20 \mathrm{~g}$ $\mathrm{L}^{-1}$, almost no hydrogen is generated, and a strong inhibition film forms on the surface of aluminum particles. L-Phenylalanine is the main raw material in food additives and one of the essential amino acids of the human body. Therefore, it is a safe, environmentally friendly and efficient inhibitor. In some engineering projects, to inhibit the hydrogen production in wet aluminum dust removal system, solutions can be prepared by adding the L-phenylalanine into the water in the wet dust collector and the concentration of L-phenylalanine solutions should not be less than $20 \mathrm{~g} \mathrm{~L}^{-1}$. Adding L-phenylalanine to a wet dust removal system can fundamentally eliminate the risk of hydrogen fire and explosions in the wet dust collector.

\section{Conflicts of interest}

There are no conflicts to declare.

\section{Acknowledgements}

The work presented in this study forms part of the research funded by the National Natural Science Foundation of China (51404063), the Fundamental Research Funds for the Central Universities (N160104010) and the National Key R \& D Project (2017YFC0805100). These funding sources are greatly appreciated. 


\section{References}

1 C. S. Liang, Z. F. Lv, Y. L. Zhu, S. A. Xu and H. Wang, Appl. Surf. Sci., 2014, 288, 497-502, DOI: 10.1016/ j.apsusc.2013.10.060.

2 X. Zhang, S. J. Ye and Q. Shen, Industrial Safety and Environmental Protection, 2015, 12, 9-11, DOI: 10.3969/ j.issn.1001-425X.2015.12.003.

3 R. K. Eckhoff, J. Loss Prev. Process Ind., 2005, 18(4-6), 225237, DOI: 10.1016/j.jlp.2005.06.012.

4 J. Taveau, S. Hochgreb, S. Lemkowitz and D. Roekaerts, J. Loss Prev. Process Ind., 2018, 51, 84-93, DOI: 10.1016/ j.jlp.2017.11.011.

5 H. Chen, Y. Zhang, H. Liu, X. Meng and W. Du, J. Loss Prev. Process Ind., 2018, 55, 19-24, DOI: 10.1016/j.jlp.2018.05.017.

6 Z. Y. Deng, Y. B. Tang, L. L. Zhu, Y. Sakka and J. Ye, Int. J. Hydrogen Energy, 2010, 35(18), 9561-9568, DOI: 10.1016/ j.ijhydene.2010.07.027.

7 S. J. Zhong, N. Miao and H. Y. Liu, Modern Occupational Safety, 2014, 10, 26-29.

8 S. S. Razavi-Tousi and J. A. Szpunar, J. Alloys Compd., 2016, 679, 364-374, DOI: 10.1016/j.jallcom.2016.04.038.

9 S. Vladimir, N. Vladimir, H. L. Ji and Y. Chungsik, Int. J. Hydrogen Energy, 2016, 41(38), 1664-1673.

10 C. R. Jung, A. Kundu, B. Ku, J. H. Gil, H. R. Lee and J. H. Jang, J. Power Sources, 2008, 175(1), 490-494, DOI: 10.1016/ j.jpowsour.2007.09.064.

11 H. Wang, Z. Wang, Z. Shi, X. Gong, J. Cao and M. Wang, Energy, 2017, 131, 98-105, DOI: 10.1016/ j.energy.2017.05.031.

12 V. Shmelev, Y. Heesung and Y. Chungsik, Int. J. Hydrogen Energy, 2016, 41(33), 14562-14572, DOI: 10.1016/ j.energy.2017.05.031.
13 V. Sheikhbahaei, E. Baniasard and G. F. Naterer, Int. J. Hydrogen Energy, 2018, 43(19), 9181-9191, DOI: 10.1016/ j.ijhydene.2018.03.196.

14 Y. Wang, K. Xu, B. Wang and J. Zhang, RSC Adv., 2017, 7(76), 47867-47876, DOI: 10.1039/c7ra05017h.

15 Y. Wang, K. Xu and L. Li, RSC Adv., 2017, 7(53), 33327-33334, DOI: $10.1039 / \mathrm{c} 7 \mathrm{ra} 04787 \mathrm{~h}$.

16 Y. Wang, K. Xu, B. Wang and Q. Wang, Int. J. Hydrogen Energy, 2018, 43(4), 2514-2523, DOI: 10.1016/ j.ijhydene.2017.12.065.

17 K. Xu, Y. Wang, R. Shen and Q. Wang, Int. J. Hydrogen Energy, 2018, 43(31), 14859-14865, DOI: 10.1016/ j.ijhydene.2018.06.024.

18 Y. Wang, H. Su, Y. Gu, X. Song and J. Zhao, OncoTargets Ther., 2017, 10, 4056-4079, DOI: 10.2147/OTT.S139262.

19 W. Z. Gai and Z. Deng, J. Power Sources, 2014, 245(1), 721729, DOI: 10.1016/j.jpowsour.2013.07.042.

20 X. W. Zheng, M. Gong, X. G. Zeng, C. M. Jian, L. J. Lu and Z. S. Jieke, Surf. Technol., 2012, 41(3), 33-36, DOI: 10.3969/ j.issn.1001-3660.2012.03.010.

21 O. Levenspiel, Chemical reaction engineering, John Wiley \&Sons, New York, 3rd edn, 1999.

22 W. Zhang and B. Wu, China Meas. Test, 2017, 43(3), 49-52, DOI: 10.11857/j.issn.1674-5124.2017.03.010.

23 J. Geng, Master Dissertation, Ocean University of China, Qingdao, 2006.

24 N. H. Helal and W. A. Badawy, Electrochim. Acta, 2011, 56(19), 6581-6587, DOI: 10.1016/j.electacta.2011.04.031.

25 W. H. Li, Q. He, C. L. Pei and B. R. Hou, Electrochim. Acta, 2007, 52(22), 6386-6394, DOI: 10.1016/ j.electacta.2007.04.077. 